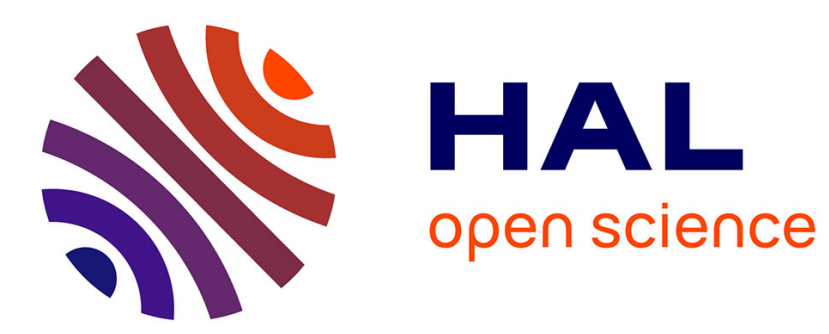

\title{
Krypton adsorption on (0001) graphite pre-plated with cyclohexane
}

\author{
A. Razafitianamaharavo, N. Dupont-Pavlovsky, A. Thomy
}

\section{To cite this version:}

A. Razafitianamaharavo, N. Dupont-Pavlovsky, A. Thomy. Krypton adsorption on (0001) graphite pre-plated with cyclohexane. Journal de Physique, 1990, 51 (1), pp.91-102. 10.1051/jphys:0199000510109100 . jpa-00212355

\section{HAL Id: jpa-00212355 https://hal.science/jpa-00212355}

Submitted on 1 Jan 1990

HAL is a multi-disciplinary open access archive for the deposit and dissemination of scientific research documents, whether they are published or not. The documents may come from teaching and research institutions in France or abroad, or from public or private research centers.
L'archive ouverte pluridisciplinaire HAL, est destinée au dépôt et à la diffusion de documents scientifiques de niveau recherche, publiés ou non, émanant des établissements d'enseignement et de recherche français ou étrangers, des laboratoires publics ou privés. 
Classification

Physics Abstracts

$68.45-64.70-68.60$

\title{
Krypton adsorption on (0001) graphite pre-plated with cyclohexane
}

\author{
A. Razafitianamaharavo $\left({ }^{1}\right)$, N. Dupont-Pavlovsky $\left({ }^{1}\right)$ and A. Thomy $\left({ }^{2}\right)$ \\ (1) CNRS, Laboratoire Maurice Letort, BP 104, 54600 Villers les Nancy, France \\ ( ${ }^{2}$ ) Laboratoire Mixte CNRS-Saint Gobain, BP 28, 54703 Pont à Mousson, France
}

(Reçu le 30 juin 1989, accepté sous forme définitive le 20 septembre 1989)

\begin{abstract}
Résumé. - La physisorption de krypton sur une surface de graphite préalablement recouverte de cyclohexane $\left(\mathrm{C}_{6} \mathrm{H}_{12}\right)$ également physisorbé a été étudiée par volumétrie entre 71 et $83 \mathrm{~K}$. L'adsorption de krypton, fortement inhibée par la présence du film préadsorbé, ne devient importante qu'à des pressions nettement plus élevées que celles observées sur graphite nu. Les résultats obtenus dans le domaine de la monocouche ont été interprétés par un déplacement partiel de $\mathrm{C}_{6} \mathrm{H}_{12}$ par le krypton et la formation de cristallites de $\mathrm{C}_{6} \mathrm{H}_{12} 3 \mathrm{D}$, ainsi qu'une miscibilité partielle des phases 2D. A plus fort taux de recouvrement, le krypton s'adsorbe sur lui-même.
\end{abstract}

\begin{abstract}
Krypton physisorption on (0001) graphite pre-plated with cyclohexane $\left(\mathrm{C}_{6} \mathrm{H}_{12}\right)$ also physisorbed has been studied between 71 and $83 \mathrm{~K}$ by means of classical volumetric methods. Krypton adsorption is strongly hindered by preadsorbed $\mathrm{C}_{6} \mathrm{H}_{12}$, and becomes significant at pressures definitely higher than on bare graphite. In the first layer range, a partial displacement of the preadsorbed $\mathrm{C}_{6} \mathrm{H}_{12}$ film by krypton adsorption, according to a first order phase transition process, was assumed, as well as $3 \mathrm{D} \mathrm{C}_{6} \mathrm{H}_{12}$ crystallites formation and partial miscibility of the $2 \mathrm{D}$ phases. At higher coverages krypton adsorbs on itself.
\end{abstract}

\section{Introduction.}

The study of composite films adsorbed on well characterized surfaces have given rise to numerous investigations within the last years, in order to determine two-dimensional (2D) phase diagrams equivalent to three-dimensional (3D) solutions and alloy diagrams [1-11].

Classical volumetric methods can be applied to the study of binary mixture adsorption by means of the pre-adsorbed layer technique, which has been introduced by Halsey and Singleton, and extended later on [1-5]. This technique is particularly suitable when the equilibrium pressures of the two gases involved in the mixture are very different, as was the case for the last system studied [5] : krypton adsorption isotherms on (0001) graphite preplated with sulfur hexafluoride $\left(\mathrm{SF}_{6}\right)$ were measured between 70 and $80 \mathrm{~K}$. At these temperatures, the krypton equilibrium pressure is more than $10^{3}$ times higher than that of $\mathrm{SF}_{6}$, and the presence of $\mathrm{SF}_{6}$ in the gas-phase can be neglected. Krypton adsorption was shown to be strongly hindered by pre-adsorbed $\mathrm{SF}_{6}$, becoming significant under pressures definitely higher than on bare graphite. Moreover, a displacement of the $\mathrm{SF}_{6}$ film by krypton 
adsorption was shown, occurring according to a first order transition process, and followed by adsorption of krypton on itself.

For comparison with the krypton- $\mathrm{SF}_{6}$ system, we have undertaken a similar study of the krypton-cyclohexane $\left(\mathrm{C}_{6} \mathrm{H}_{12}\right)$ system on the same substrate. $\mathrm{C}_{6} \mathrm{H}_{12}$ has been chosen because of its very low saturating vapour pressure (about $10^{-15}$ torr), even compared to that of $\mathrm{SF}_{6}$ (about $10^{-7}$ torr) in the temperature range of the binary mixture investigation, which confers an utmost character to the (krypton- $\mathrm{C}_{6} \mathrm{H}_{12}$ ) system. $\mathrm{C}_{6} \mathrm{H}_{12}$ pre-plating of graphite could then be expected to lead to the formation of a film stable in presence of krypton, which would be equivalent to a new substrate.

Experiments were performed on exfoliated graphite (manufactured by « Carbone Lorraine ») which exhibits a very homogeneous surface of $45 \mathrm{~m}^{2} \cdot \mathrm{g}^{-1}$ specific area.

Before discussing the results, the main $3 \mathrm{D}$ and $2 \mathrm{D}$ properties of both adsorbates, which are needed for the composite film study, and the experimental procedure are presented.

\section{Adsorbates.}

2.1 PURITY. - Krypton of $99.94 \%$ purity was supplied by « L'Air Liquide ». Cyclohexane was a Merck product of $99.7 \%$ purity. The adsorbates were purified before each experiment by pumping on the condensed phase inside the introduction system at $77 \mathrm{~K}$ for krypton, and $193 \mathrm{~K}$ (dry ice temperature) for $\mathrm{C}_{6} \mathrm{H}_{12}$.

2.2 3D PROPERTIES. - The 3D triple point and critical temperatures are 115.8 and $209.4 \mathrm{~K}$ for krypton and 279.7 and $554 \mathrm{~K}$ for $\mathrm{C}_{6} \mathrm{H}_{12}$ respectively.

The dependence of saturating vapour pressures on temperature are given by the equations :

$$
\log _{10} P_{0}(\text { torr })=-\frac{588.7}{T}+7.85
$$

between 72 and $91 \mathrm{~K}$ for krypton [12], and

$$
\log _{10} P_{0}(\text { torr })=-\frac{2040}{T}+8.94
$$

between 203 and $248 \mathrm{~K}$ for $\mathrm{C}_{6} \mathrm{H}_{12}$ [13].

Equation (2) cannot be used in the temperature range of the composite film investigation (70-83 K) because $\mathrm{C}_{6} \mathrm{H}_{12}$ undergoes a phase transition from a cubic close packed structure, stable between 279.8 and $186 \mathrm{~K}$ to a monoclinic structure stable at lower temperatures [14]. This is why we have determined the dependence of saturating vapour pressure on temperatures between 147 and $185 \mathrm{~K}$, where the structure of $3 \mathrm{D} \mathrm{C}_{6} \mathrm{H}_{12}$ is the same as that observed at the temperature of the composite film study:

$$
\log _{10} P(\text { torr })=-\frac{1700 \pm 50}{T}+7.25 \pm 0.3 .
$$

The value of the saturating vapour pressure, calculated by means of equation (3), is $2 \times 10^{-15}$ torr at $77 \mathrm{~K}$, which is negligible, compared with the krypton vapour pressure at the same temperature (1.72 torr after Eq. (1)). Consequently, the presence of $\mathrm{C}_{6} \mathrm{H}_{12}$ in the gasphase is not taken into account in the temperature range of krypton isotherms measurements on $\mathrm{C}_{6} \mathrm{H}_{12}$ pre-plated graphite $(70-83 \mathrm{~K})$.

2.3 2D PROPERTIES. - Pure krypton adsorption properties on graphite have been extensively studied [15-17]. Discrete layers may form on the substrate, no matter how thick the film, 
according to a complete wetting process. Up to five vertical steps are observed on the $77 \mathrm{~K}$ isotherm, which are representative of the condensation of the first five monomolecular layers, according to a first order phase transition process. The dependence on temperature of the first three steps pressure is given in table $\mathrm{I}$.

Table I. $-A_{i}$ and $B_{i}$ coefficients of the relations $\log _{10} P_{i}$ (torr) $=-\frac{A_{i}}{T}+B_{i}$ for the first three steps of krypton adsorption isotherms.

\begin{tabular}{|c|c|c|c|c|}
\hline$i$ & $A_{i}$ & $B_{i}$ & $A_{i}{ }^{*}$ & $B_{i}^{*}$ \\
\hline 1 & $860.4^{(\mathrm{a})}$ & $7.78^{(\mathrm{a})}$ & & \\
\hline 2 & $602^{(\mathrm{b})}$ & $7.63^{(\mathrm{b})}$ & 622 & 7.84 \\
\hline 3 & $597^{(\mathrm{c})}$ & $7.60^{(\mathrm{c})}$ & & 7.85 \\
\hline
\end{tabular}

$i \quad$ : number of the step

(a) : after [16]

(b) : after [17]

(c) : our measurements.

$A_{i}^{*}$ and $B_{i}{ }^{*}$ are estimated values assuming a $1 / i^{3}$ decrease of the adsorption potential and perpendicular entropy with increasing number of layers.

$$
A_{i}=A_{0}+\left(A_{1}-A_{0}\right) / i^{3} ; \quad \text { ibid for } B_{i} ;
$$

$A_{0}$ and $B_{0}$ are A and B coefficients for the saturating vapour pressure ; cf. [17].

In the monolayer range, krypton condensation leads to a commensurate $\sqrt{3} \cdot \sqrt{3} \cdot \mathrm{R} 30^{\circ} 2 \mathrm{D}$ solid. Near the monolayer completion, this solid changes into an incommensurate structure of higher density. The krypton cross section at the monolayer completion is $14.7 \AA^{2}$ at $77 \mathrm{~K}$, as determined from volumetric and LEED measurements [9, 18].

Pure $\mathrm{C}_{6} \mathrm{H}_{12}$ adsorption properties have been studied by means of isotherm measurements [13, 19-21]. In the last investigation [21], which is also the most complete, a set of isotherms has been measured in the 203-293 K temperature range. The isotherms exhibit two steps, representative of the adsorption of two layers before $3 \mathrm{D}$ condensation. From the temperature dependence of the second step pressure, the second layer completion was assumed to occur above $145 \mathrm{~K}$, only one dense monolayer being adsorbed before 3D condensation at lower temperatures. This assumption was corroborated by recent structural investigations [22]. Figure 1 shows a schematic diagram of an adsorption isotherm at $233 \mathrm{~K}$. One of its characteristic features is the slope of the plateau, which corresponds to a difference of $20 \%$ in the total adsorbed amount between the end of the first step, and the beginning of the second. In [21], the completion of the monolayer was located at the beginning of the plateau (M point of Fig. 1), the adsorbed molecule cross section being then $36.75 \AA^{2}$.

\section{Experimental procedure.}

The preadsorbed layer technique is grounded on the difference in condensation properties of the two gases involved in the film : $\mathrm{C}_{6} \mathrm{H}_{12}$ is adsorbed first at a temperature of $233 \mathrm{~K}$. This 


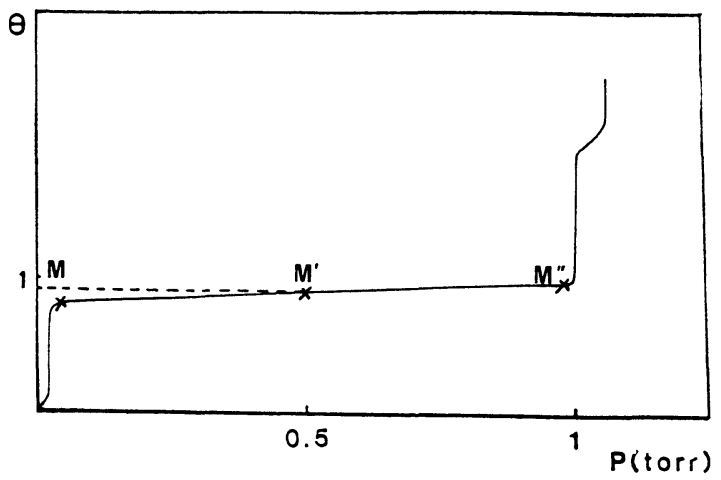

Fig. 1. - Schematic drawing of $\mathrm{a}_{6} \mathrm{H}_{12}$ adsorption isotherm on graphite at $233 \mathrm{~K}$. $\theta$ is the cyclohexane fractional coverage.

temperature, arbitrarily chosen, is high enough to enable the adsorption equilibrium control $[13,21]$. The sample is then slowly cooled $(0.5$ degree per minute), in order to avoid any distillation on the cell walls, down to the krypton adsorption temperature. Two problems had then to be solved before carrying on this investigation. First, what is the adsorbed $\mathrm{C}_{6} \mathrm{H}_{12}$ amount corresponding to a complete monolayer ? Second, at what temperature should krypton adsorption be performed?

A difference of $20 \%$ in the $\mathrm{C}_{6} \mathrm{H}_{12}$ adsorbed amount is observed between the beginning and the end of the plateau of the adsorption isotherm (points $M$ and $M^{\prime \prime}$ in Fig. 1). In order to

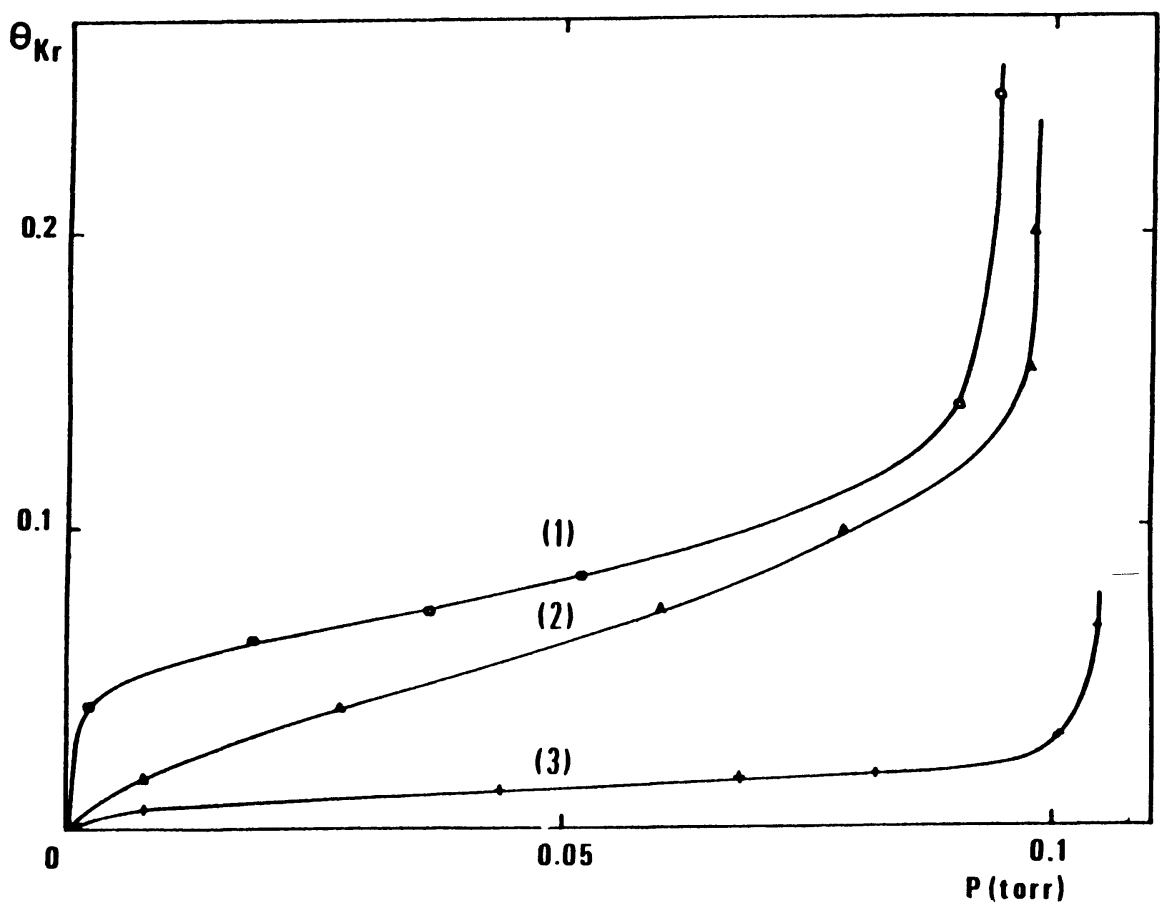

Fig. 2. - Initial stages of krypton adsorption at $77 \mathrm{~K}$ on $\mathrm{C}_{6} \mathrm{H}_{12}$ pre-plated graphite. (1), (2) and (3) correspond to $\mathrm{C}_{6} \mathrm{H}_{12}$ coverages at $M, \mathbf{M}^{\prime}$ and $\mathbf{M}^{\prime \prime}$ points respectively on the isotherm of figure 1 . $\theta_{\mathrm{Kr}}$ is the fractional coverage of krypton on bare graphite. 
define the location of the monolayer completion the low-coverage isotherm shape of krypton on $\mathrm{C}_{6} \mathrm{H}_{12}$ pre-plated graphite at $77 \mathrm{~K}$ was examined for several preadsorbed amounts. Results are shown in figure 2 . When graphite is pre-plated with $\mathrm{C}_{6} \mathrm{H}_{12}$ amounts corresponding to $M^{\prime}$ and $M^{\prime \prime}$ points in figure 1 , the linear Henry law is observed during the initial stages of krypton adsorption (curves (2) and (3), Fig. 2). For the lowest coverage considered (M point), the Henry law is not obeyed. These observations can be explained by assuming that the $\mathrm{C}_{6} \mathrm{H}_{12}$ monolayer is not complete at point $\mathrm{M}$. Consequently, the graphite surface preplated with such a $\mathrm{C}_{6} \mathrm{H}_{12}$ coverage is not uniform with respect to krypton adsorption. The monolayer coverage was then set at point $\mathbf{M}^{\prime}$, in the middle of the plateau between the two isotherm steps.

Curves shown in figure 3 are obtained by introducing krypton at $77 \mathrm{~K}$ for isotherm measurements on a graphite surface pre-plated at $233 \mathrm{~K}$ with a $\mathrm{C}_{6} \mathrm{H}_{12}$ monolayer. The adsorption isotherm exhibits three vertical steps and an accident in the second plateau. The desorption isotherm exhibits steps at the same pressures, but the two curves cannot be superposed. Desorption plateaus occur for higher adsorbed amounts, and the accident observed in the second plateau of the adsorption isotherm does not appear on the desorption curve. The irreversibility may be assigned to an out-of-equilibrium state of the film during krypton adsorption. Such an assumption is corroborated by kinetic observations : quite a long time is necessary to reach the equilibrium pressure after admission of krypton amounts corresponding to the upper part of the isotherm first step (more than one hour, after each gas introduction, instead of less than 15 min for pure krypton adsorption). In order to increase

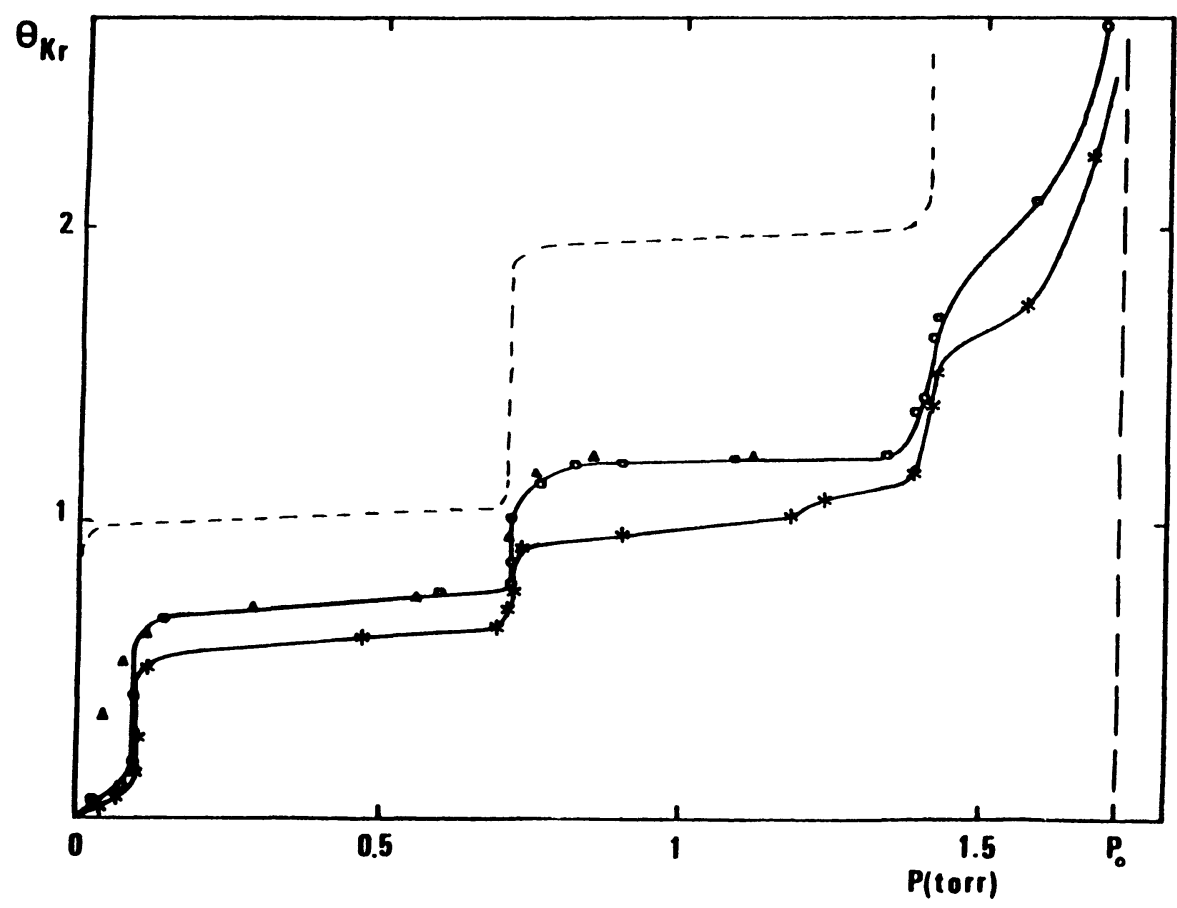

Fig. 3. - Adsorption and desorption isotherms of krypton at $77 \mathrm{~K}$ on graphite pre-plated with a $\mathrm{C}_{6} \mathrm{H}_{12}$ monolayer. Krypton introduction at $77 \mathrm{~K}(*)$ adsorption ; $(\Delta)$ desorption. Krypton introduction at $150 \mathrm{~K}:(\square)$. Dotted line : krypton on bare graphite. $\theta_{\mathrm{Kr}}$ : fractional coverage of krypton on bare graphite. $P_{0}$ : saturating vapour pressure of krypton. 
the adsorbate mobility, the sample was heated to $150 \mathrm{~K}$ before each krypton introduction. The isotherm was measured at $77 \mathrm{~K}$, and results are shown in figure 3 . The binary mixture adsorption is then reversible, except for the first isotherm step, which will be discussed later. Moreover, the adsorption isotherm coincides with the desorption curve obtained after introducing krypton at $77 \mathrm{~K}$. The second experimental procedure was then adopted and assumed to yield an equilibrium distribution of atoms on the surface. The accident observed in the isotherm second plateau when introducing krypton at $77 \mathrm{~K}$ was assigned to a metastable state of the film. Such a temperature effect has already been observed, and annealings of the sample are frequently carried out in order to reach the layer equilibrium state in binary mixture adsorption studies [6-9].

\section{Results and discussion.}

4.1 AdSORPTION OF KRYPTON AT 77.3 K ON GRAPHITE PRE-PLATED WITH A $\mathrm{C}_{6} \mathrm{H}_{12}$ MONOLAYER. - The krypton adsorption isotherm at $77.3 \mathrm{~K}$ obtained under equilibrium conditions (krypton introduction at $150 \mathrm{~K}$ ) on graphite pre-plated with a $\mathrm{C}_{6} \mathrm{H}_{12}$ monolayer, exhibits three vertical steps. Its comparison with the adsorption isotherm of pure krypton at the same temperature bears on two main points : step pressures and step heights (Fig. 3).

The first step pressure is two hundred times higher than on bare graphite, which indicates that krypton adsorption is strongly hindered by pre-adsorbed $\mathrm{C}_{6} \mathrm{H}_{12}$, whereas the second and third step pressure values are very close to those obtained for krypton adsorption on bare graphite. Such a feature has already been observed for the (krypton-SF $_{6} /$ graphite system [5]. It was assumed to result from a $\mathrm{SF}_{6}$ film displacement produced by krypton adsorption, according to a first order transition process. The similarity of krypton isotherms on bare and $\mathrm{SF}_{6}$ pre-plated graphite after the first vertical step was assigned to krypton growing on itself. The same interpretation can be given to our results.

The irreversibility shown by the krypton desorption curve in the first step range may be explained by the same assumption : as the $\mathrm{C}_{6} \mathrm{H}_{12}$ saturating vapour pressure is very low at $77 \mathrm{~K}$ (about $10^{-15}$ torr), the exchanges with the gas-phase are negligible. At least, part of the $3 \mathrm{D} \mathrm{C}_{6} \mathrm{H}_{12}$ crystallites formed during adsorbed $\mathrm{C}_{6} \mathrm{H}_{12}$ displacement by krypton adsorption cannot re-distillate to the $2 \mathrm{D}$ phase, even when krypton is desorbed. The shape in the initial part of the isotherm would then represent the adsorptive properties of krypton on a graphite surface only partially pre-plated with $\mathrm{C}_{6} \mathrm{H}_{12}$.

But the similarity between $\mathrm{Kr}-\mathrm{SF}_{6}$ and $\mathrm{Kr}-\mathrm{C}_{6} \mathrm{H}_{12}$ couples is not so close as far as we are concerned about the step heights. As a matter of fact, the krypton adsorption isotherm on graphite pre-plated with a $\mathrm{SF}_{6}$ monolayer exhibits at $77.3 \mathrm{~K}$ steps of equal height, $83 \%$ that of pure krypton isotherm steps [5]. The authors assigned this difference in height to 3D $\mathrm{SF}_{6}$ formed during the film displacement, and covering a part of the surface which is no longer accessible to krypton. This assumption cannot be applied to our case, owing to the larger difference observed. The first step height of krypton isotherm at $77.3 \mathrm{~K}$ on $\mathrm{C}_{6} \mathrm{H}_{12}$ pre-plated graphite is $70 \%$ that on bare graphite, and those of the second and third steps only $50 \%$. If the non-accessibility to krypton of $30 \%$ of the total uniform surface area in the first layer range were solely attributed to displaced $\mathrm{C}_{6} \mathrm{H}_{12}$, it would correspond to a three-layer thick film. Thermodynamical and structural studies of pure $\mathrm{C}_{6} \mathrm{H}_{12}$ adsorptive properties have shown that only one monolayer can be adsorbed at $77.3 \mathrm{~K}$ before $3 \mathrm{D}$ condensation [13, 21, 22]. Moreover, a three-layer thickness is not large enough to be representative of a 3D phase. This is why our explanation is that the $\mathrm{C}_{6} \mathrm{H}_{12}$ film displacement by krypton is not complete, part of the $2 \mathrm{D}$ preadsorbed $\mathrm{C}_{6} \mathrm{H}_{12}$ remaining on the surface. The most probable reason for such a partial displacement is the krypton- $\mathrm{C}_{6} \mathrm{H}_{12}$ miscibility in the adsorbed phase. The decrease in 
the isotherm heights of the second and third steps with respect to the first could be explained by assuming that $2 \mathrm{D} \mathrm{C}_{6} \mathrm{H}_{12}$ in solution with krypton in the first adsorbed layer produces repulsive sites for krypton adsorption in the upper layers, resulting in a new decrease of the uniform surface accessible to krypton.

4.2 InfluenCE OF $\mathrm{C}_{6} \mathrm{H}_{12}$ FRACTIONAL COVERAGE. - Krypton adsorption isotherms at temperatures near to $77 \mathrm{~K}$ on graphite pre-plated with $0.1,0.48,0.7$ and $0.77 \mathrm{C}_{6} \mathrm{H}_{12}$ monolayer are shown in figure 4. The only differences with the isotherm obtained on a complete $\mathrm{C}_{6} \mathrm{H}_{12}$ monolayer lie in the first layer range : the first step separates into two substeps, whose relative heights depend on $\mathrm{C}_{6} \mathrm{H}_{12}$ coverage. The higher the $\mathrm{C}_{6} \mathrm{H}_{12}$ coverage, the more developed the second sub-step. It is located at the same pressure as that of the krypton isotherm first step on a complete $\mathrm{C}_{6} \mathrm{H}_{12}$ monolayer and is representative of the same phenomenon : displacement of the $\mathrm{C}_{6} \mathrm{H}_{12}$ film by krypton adsorption.

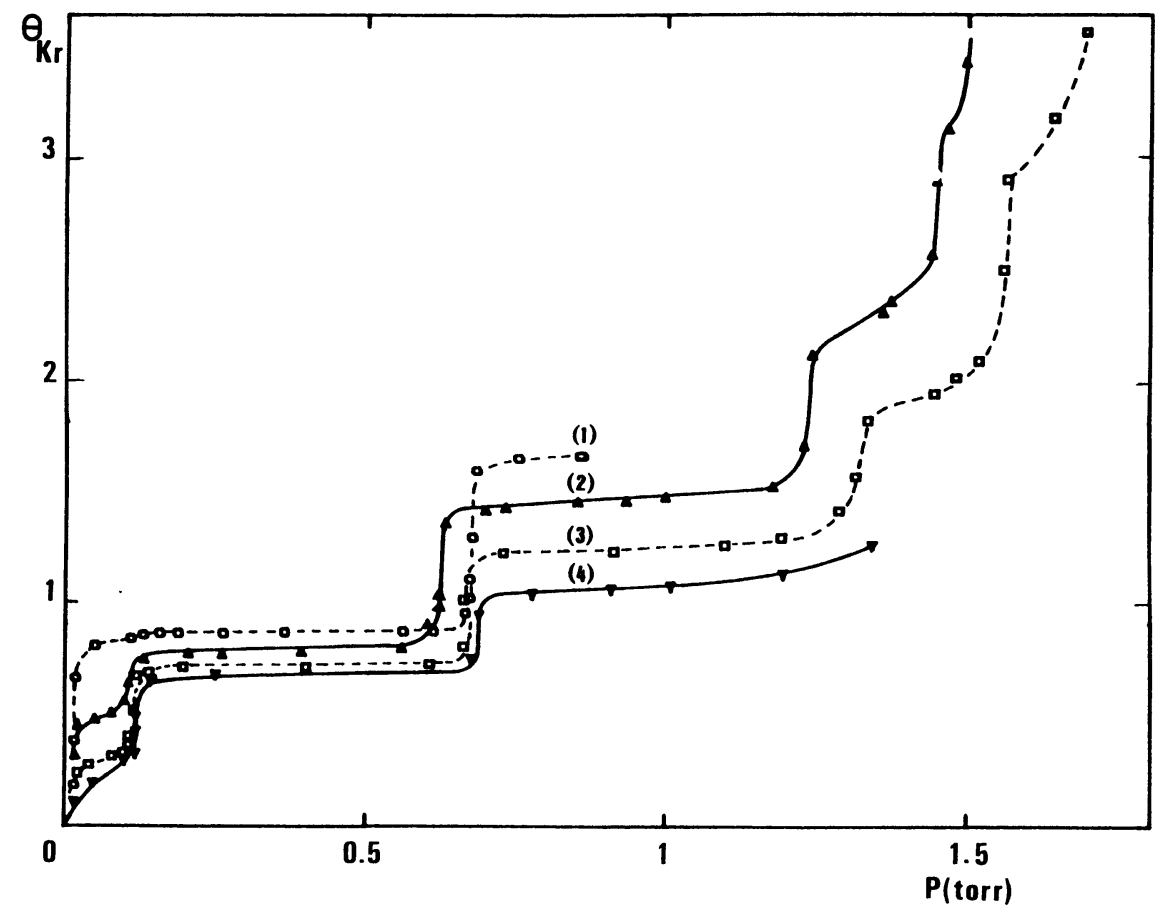

Fig. 4. - Krypton adsorption isotherms on $\mathrm{C}_{6} \mathrm{H}_{12}$ pre-plated graphite (1) : $0.1 \mathrm{C}_{6} \mathrm{H}_{12}$ monolayer $77.3 \mathrm{~K}$; (2) : $0.48 \mathrm{C}_{6} \mathrm{H}_{12}$ monolayer $77 \mathrm{~K}$; (3) : $0.7 \mathrm{C}_{6} \mathrm{H}_{12}$ monolayer $77.24 \mathrm{~K}$; (4) : $0.77 \mathrm{C}_{6} \mathrm{H}_{12}$ monolayer 77.37 K. $\theta_{\mathrm{Kr}}=$ fractional coverage of krypton.

A detailed representation of the initial parts of the isotherms is given in figure 5. For 0.1 and $0.48 \mathrm{C}_{6} \mathrm{H}_{12}$ fractional coverages, a step clearly appears at the same pressure as that of pure krypton isotherm first step, and can be assigned to preliminary krypton adsorption on the bare part of the surface. The shape of the curve obtained with 0.7 monolayer of pre-adsorbed $\mathrm{C}_{6} \mathrm{H}_{12}$ is probably the consequence of an increase of the surface heterogeneity towards krypton with increasing $\mathrm{C}_{6} \mathrm{H}_{12}$ coverage. In conclusion, krypton is first adsorbed on the bare part of the graphite surface, whatever the $\mathrm{C}_{6} \mathrm{H}_{12}$ fractional coverage in the submonolayer range. 


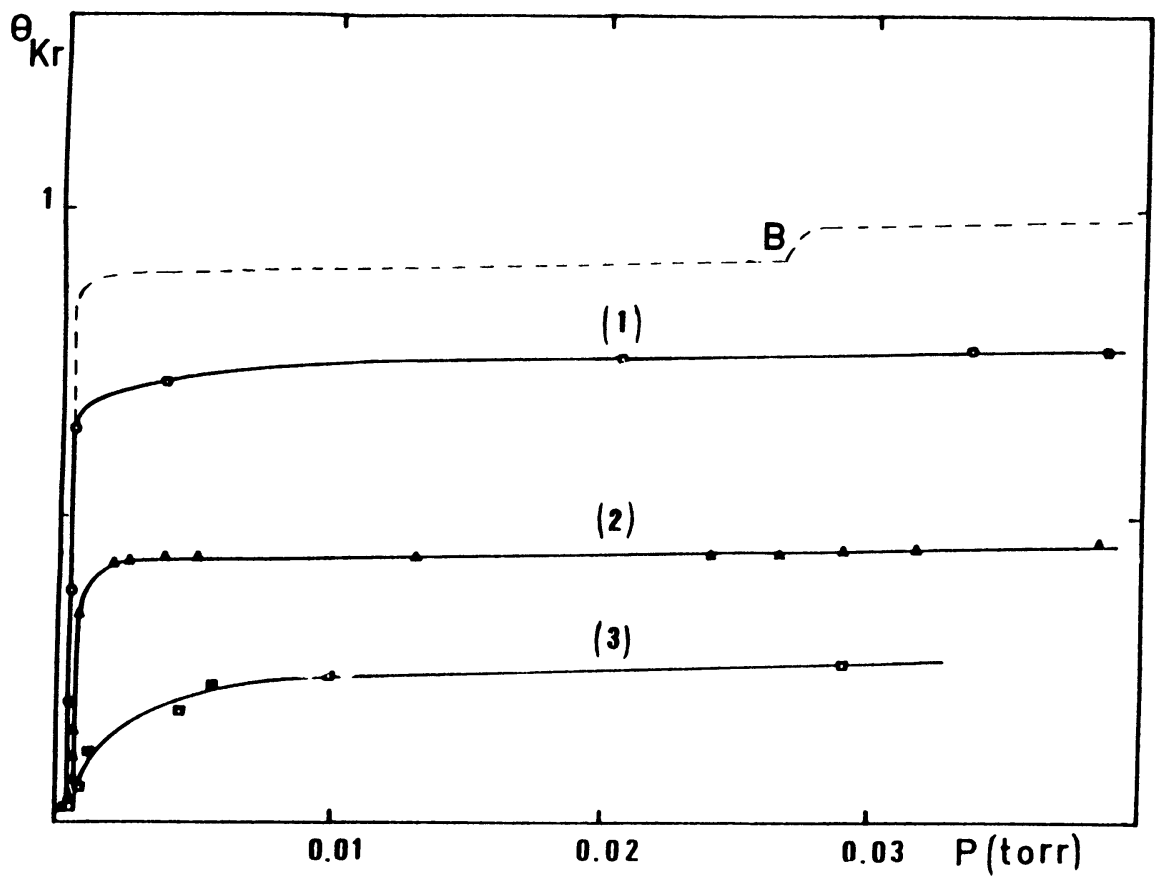

Fig. 5. - Krypton adsorption isotherms on $\mathrm{C}_{6} \mathrm{H}_{12}$ pre-plated graphite. Detailed representation of the first sub-step. (1) $0.1 \mathrm{C}_{6} \mathrm{H}_{12}$ monolayer $77.3 \mathrm{~K}$. (2) $0.48 \mathrm{C}_{6} \mathrm{H}_{12}$ monolayer $77 \mathrm{~K}$. (3) $0.7 \mathrm{C}_{6} \mathrm{H}_{12}$ monolayer $77.24 \mathrm{~K}$. Dotted line : krypton on bare graphite. $\theta$ fractional coverage of krypton on bare graphite.

However, the commensurate-incommensurate transition occurring near the completion of a pure krypton monolayer (B point in Fig. 5) does not appear for the composite film, even when $0.1 \mathrm{C}_{6} \mathrm{H}_{12}$ monolayer is pre-adsorbed. A similar study of the (krypton-xenon)/graphite system has shown that for krypton adsorption on 0.1 xenon pre-adsorbed monolayer, the commensurate-incommensurate transition still appears and is moved towards higher pressures [4]. Thus we think that this transition actually does not occur for the (krypton$\mathrm{C}_{6} \mathrm{H}_{12}$ )/graphite system. Moreover, as the krypton isotherm first substep pressure is that of pure krypton commensurate $2 \mathrm{D}$ solid condensation, pre-plated $\mathrm{C}_{6} \mathrm{H}_{12}$ probably results in a stabilization of krypton commensurate $2 \mathrm{D}$ solid. Such a stabilization of a commensurate phase by larger molecules has already been observed [4-8, 9] in adsorption studies of composite films when the two components of the film are miscible. This corroborates our assumption concerning the solubility of $\mathrm{C}_{6} \mathrm{H}_{12}$ in krypton.

It should also be noted that in the first layer range, krypton adsorption isotherm on 0.7 $\mathrm{C}_{6} \mathrm{H}_{12}$ layer pre-plated graphite is very similar in shape to krypton desorption isotherm on one $\mathrm{C}_{6} \mathrm{H}_{12}$ layer pre-plated graphite, in accordance with the assumption of a partially irreversible displacement of $\mathrm{C}_{6} \mathrm{H}_{12}$ by krypton, as proposed in paragraph 4.1.

4.3. DEPENDENCE ON TEMPERATURE. - Krypton adsorption isotherms on graphite preplated with one $\mathrm{C}_{6} \mathrm{H}_{12}$ monolayer, measured at $71,77.5$ and $83 \mathrm{~K}$, are reported in figure 6 . The general shapes of isotherms are very similar at the three temperatures considered, except for the first step, which is no longer vertical at $83 \mathrm{~K}$. The different step pressures are reported in table II and compared with those for krypton adsorbed on bare graphite at the same temperatures. The pressure values for pure krypton are calculated by means of the equation : 


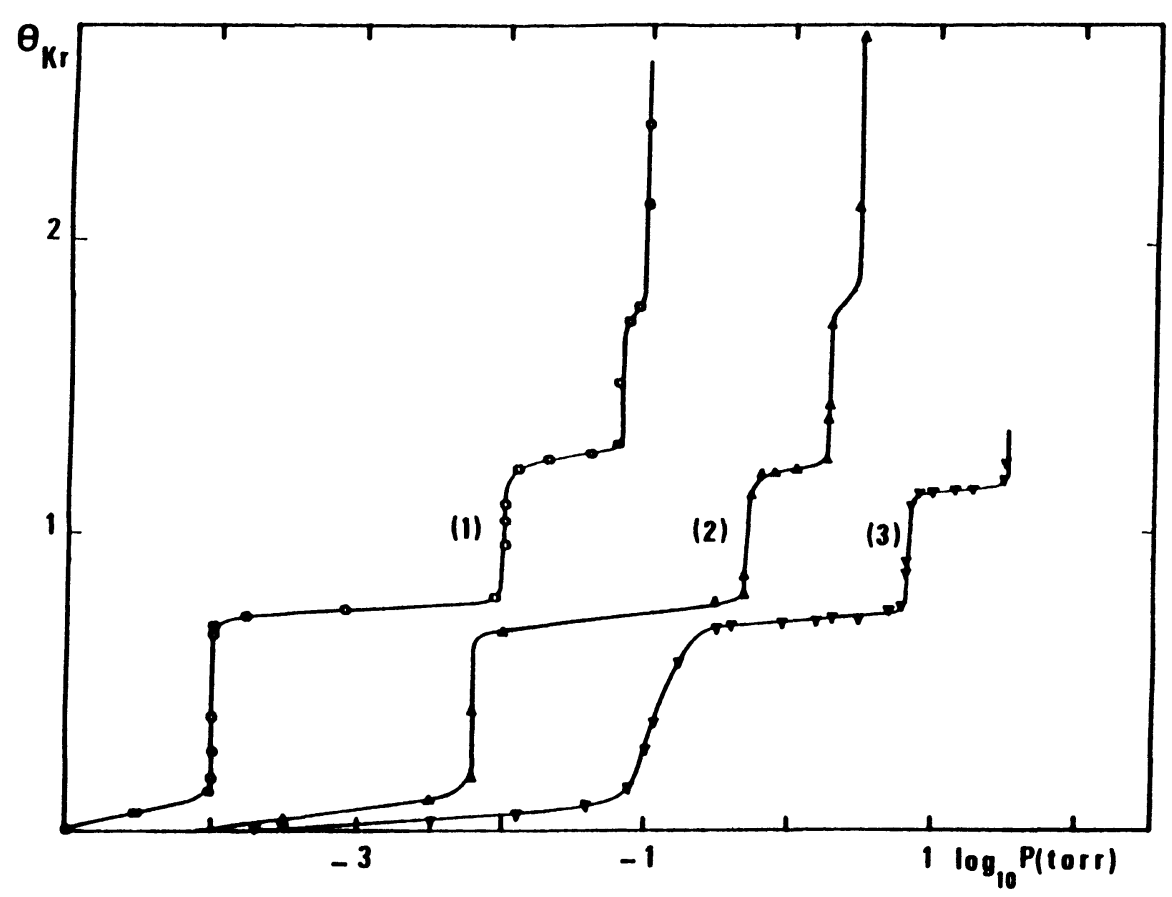

Fig. 6. - Krypton adsorption isotherms on graphite pre-plated with a $\mathrm{C}_{6} \mathrm{H}_{12}$ monolayer. (1) $71 \mathrm{~K}$, (2) $77.5 \mathrm{~K}$, (3) $83 \mathrm{~K}$. $\theta_{\mathrm{Kr}}$ fractional coverage of krypton on bare graphite.

Table II. - Step pressures of krypton isotherm steps on bare and monolayer $\mathrm{C}_{6} \mathrm{H}_{12}$ pre-plated graphite. $P_{1}, P_{2}$ and $P_{3}$ are the pressures of the first, second and third steps respectively.

\begin{tabular}{|l|c|c|c|c|c|c|}
\hline \multirow{2}{*}{$T(\mathrm{~K})$} & \multicolumn{3}{|c|}{$\mathrm{Kr} / \mathrm{Gr}$} & \multicolumn{3}{c|}{$\mathrm{Kr} / \mathrm{C}_{6} \mathrm{H}_{12} / \mathrm{Gr}$} \\
\cline { 2 - 7 } & $P_{1}$ (torr) & $P_{2}$ (torr) & $P_{3}$ (torr) & $P_{1}$ (torr) & $P_{2}$ (torr) & $P_{3}$ (torr) \\
\hline 71 & $5 \times 10^{-5}$ & 0.138 & 0.270 & $1.8 \times 10^{-2}$ & 0.135 & 0.295 \\
\hline 77.50 & $5 \times 10^{-4}$ & 0.703 & 1.336 & 0.110 & 0.720 & 1.410 \\
\hline 83 & $2.60 \times 10^{-3}$ & 2.28 & 4.25 & 0.380 & 2.350 & \\
\hline
\end{tabular}

$$
\log \left(P_{i}\right)=-\frac{A_{i}}{T}+B_{i}
$$

with $A_{i}$ and $B_{i}$ taken in table $\mathrm{I}$, where $i$ is the number of the step. $A_{1}$ and $B_{1}$ are taken from [16], $A_{2}, A_{3}, B_{2}, B_{3}$ from our measurements.

At the above temperatures, the second and third step pressure values are very similar on bare and pre-plated graphite, whereas the first step pressure is much higher on pre-plated graphite. Coefficients of equation (4) determined from the step pressures of krypton isotherms on pre-plated graphite are reported in table III. The comparison of their values 
Table III. $-A_{i}$ and $B_{i}$ coefficients of the relations $\log _{10} P_{i}$ (torr) $=-\frac{A_{i}}{T}+B_{i}$ for the first three steps of krypton adsorption isotherms on monolayer $\mathrm{C}_{6} \mathrm{H}_{12}$ pre-plated graphite. $i$ is the number of the step.

\begin{tabular}{|c|c|c|}
\hline$i$ & $A_{i}$ & $B_{i}$ \\
\hline 1 & 650 & 7.50 \\
\hline 2 & 610 & 7.72 \\
\hline 3 & 583 & 7.65 \\
\hline
\end{tabular}

with those for a pure krypton film (Tab. I) corroborates the above observations : the adsorptive properties of krypton on $\mathrm{C}_{6} \mathrm{H}_{12}$ pre-plated graphite differ from those on bare graphite mainly in the first layer range.

In so far as the substrate (graphite $+\mathrm{C}_{6} \mathrm{H}_{12}$ ) is not invariant with respect to krypton adsorption, and part of $\mathrm{C}_{6} \mathrm{H}_{12}$ is probably in solution with krypton, it seems hazardous to apply to the composite film the $2 \mathrm{D}$ phase thermodynamical relations established for pure adsorbed films. It should be noticed that the calculation of the isosteric heat of adsorption, according to the relation

$$
Q_{\mathrm{st}}=2.3 R A_{1}
$$

leads to a lower value $\left(Q_{\mathrm{st}}=12.4 \mathrm{~kJ} . \mathrm{mole}^{-1}\right)$ than that corresponding to pure krypton adsorption in the first layer range $\left(Q_{\mathrm{st}}=16.5 \mathrm{~kJ}\right.$. mole $\left.{ }^{-1}\right)$, as has already been observed for the (krypton- $\mathrm{SF}_{6}$ )/graphite system [5]. As for this last system, the difference can be mainly assigned to the displacement of the preadsorbed layer. It would be worth checking the validity of these $Q_{\text {st }}$ values by means of calorimetric measurements. Unfortunately, this is presently impossible, due to technical reasons.

\section{Conclusion.}

From these results, a mechanism can be proposed for the composite film organization, when krypton is adsorbed on a (0001) graphite surface pre-plated with a $\mathrm{C}_{6} \mathrm{H}_{12}$ monolayer.'A schematic drawing of its successive stages is presented in figure 7. The initial stage (OA part of the isotherm) would be $2 \mathrm{D}$ krypton gas adsorption on the $\mathrm{C}_{6} \mathrm{H}_{12}$ monolayer. Krypton adsorption on the graphite surface itself would only begin in the curved $A B$ part of the isotherm, with a possible compression of the $\mathrm{C}_{6} \mathrm{H}_{12}$ film. Displacement of $2 \mathrm{D} \mathrm{C}_{6} \mathrm{H}_{12}$ would occur according to a first order phase transition process, represented by the vertical $\mathrm{BC}$ part of the isotherm first step. The two coexisting $2 \mathrm{D}$ solid phases would be the compressed $\mathrm{C}_{6} \mathrm{H}_{12}$ film, and a $\mathrm{C}_{6} \mathrm{H}_{12}-\mathrm{Kr}$ solution rich in krypton, whose extent would increase with increasing krypton coverage, while $2 \mathrm{D}$ compressed $\mathrm{C}_{6} \mathrm{H}_{12}$ would transform into 3D crystallites, until reaching the first layer completion. The second and third isotherm steps would be representative of krypton adsorption on itself.

Concerning the structure of the krypton rich phase in the first monolayer, from the experiments performed on submonolayer $\mathrm{C}_{6} \mathrm{H}_{12}$ coverages, a stabilization of the $\sqrt{3} \cdot \sqrt{3}$ $\mathrm{R} 30^{\circ}$ commensurate phase has been assumed which could be preserved even in the $\mathrm{C}_{6} \mathrm{H}_{12}$ displacement phase transition. 

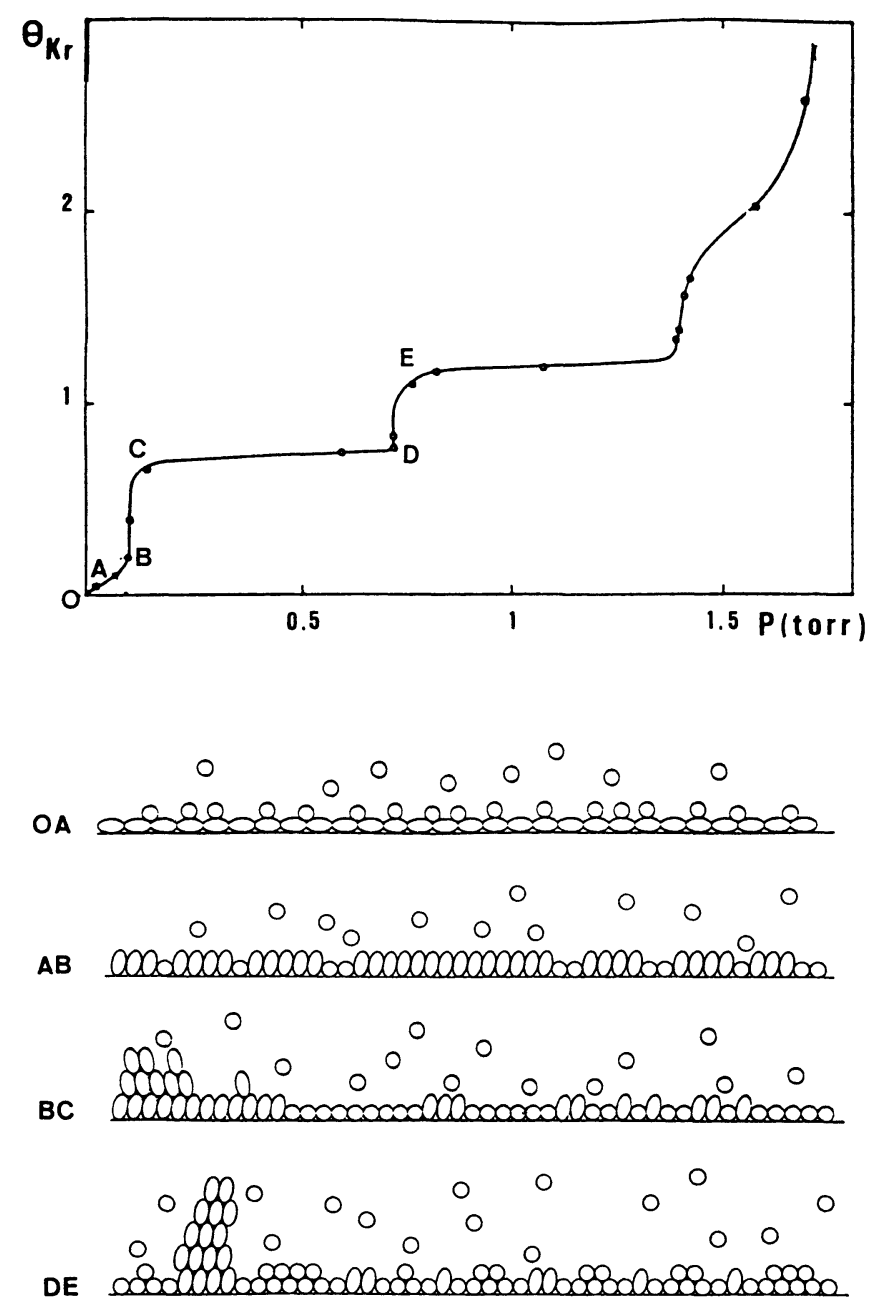

Fig. 7. - Schematic drawing on the composite film organisation. (O) krypton. (๑) cyclohexane.

We intend to verify all these assumptions by a structural characterization of the $\left(\mathrm{Kr}-\mathrm{C}_{6} \mathrm{H}_{12}\right) /$ graphite system, scattering techniques beginning to be applied to the study of composite physisorbed films [6-11].

The last point to be noticed concerns the number of steps exhibited by krypton adsorption isotherms at $77 \mathrm{~K}$ on pre-plated graphite. Only three steps can be distinguished for krypton adsorption on graphite pre-plated with a $\mathrm{C}_{6} \mathrm{H}_{12}$ monolayer, instead of five for krypton on bare graphite. Such a decrease of the step number can be assigned to the surface heterogeneity produced by $\mathrm{C}_{6} \mathrm{H}_{12}$ pre-plating, in agreement with Price and Venables [23]. These authors have shown that the number of rare gas adsorbed layers on the clivage faces of graphite is very sensitive to the surface uniformity and cleanliness. For $\mathrm{C}_{6} \mathrm{H}_{12}$ pre-coverages lower than about 0.5 monolayer, four steps are to be seen on the krypton isoterm, which would indicate that surface heterogeneity decreases with decreasing $\mathrm{C}_{6} \mathrm{H}_{12}$ coverage.

In conclusion, despite its saturating vapour pressure, much lower than that of $\mathrm{SF}_{6}$, preplated $\mathrm{C}_{6} \mathrm{H}_{12}$ is also displaced, and does not form a stable film. 


\section{Acknowledgment.}

The authors are grateful to Professor X. Duval for helpful discussions.

\section{References}

[1] Singleton J. H., Halsey J. G. Jr., J. Phys. Chem. 58 (1954) 330.

[2] Steele W. A., Aston J. G., J. Phys. Chem. 23 (1955) 1547.

[3] Prenslow C. F., Beard H. R., Brundage B. S., J. Chem. Phys. 75 (1969) 968.

[4] Regnier J., Bockel C., Dupont-Pavlovsky N., Surf. Sci. 112 (1981) L770.

[5] Bouchdoug M., Menaucourt J., Thomy A., J. Phys. France 47 (1986) 1797.

[6] Stephens P. W., Goldmann A. J., Heiney P. A., Bancel P. A., Phys. Rev. B 33 (1986) 655.

[7] Bohr J., Nielsen M., Alsnielsen J., KJaer K., Mc Tague J., Surf. Sci. 125 (1983) 181.

[8] Migone A. D., Li Z. H., Chan M. H. W., Giri M. R., Phys. Rev. B 28 (1983) 6525.

[9] Ceva T., Goldmann M., Marti C., J. Phys. France 47 (1986) 1527.

[10] You H., Fain S. C., Satija S. K., Passel L., Phys. Rev. Lett. 56 (1986) 244.

[11] Satija K. S., Passel L., Wicksted J., Physica 136 B (1986) 7.

[12] LaRher Y., J. Chim. Phys. 65 (1968) 1683.

[13] Khatir Y., Coulon M., Bonnetain L., J. Chim. Phys. 75 (1978) 796.

[14] Kahn R., Fourme R., Andre D., Renaud M., Acta Cryst. B 39 (1973) 131.

[15] Thomy A., Duval X., Regnier J., Surf. Sci. Rept. 1 (1981) 1.

[16] Larher Y., J. Chem. Soc. Faraday Trans. 170 (1974) 320.

[17] Тномy A., Duval X., J. Chim. Phys. 67 (1970) 1101.

[18] Chinn M. D., Fain S. C. Jr. Phys. Rev. Lett. 39 (1977) 146.

[19] Smith R. N., Pierce C., Cordes H., J. Amer. Chem. Soc. 72 (1960) 5595.

[20] Ewin B., Pierce C., J. Phys. Chem. 71 (1967) 3408.

[21] Delachaume J. C., Thesis, Grenoble (1985).

[22] Razafitianamaharavo A., Convert P., Coulomb J. P., Croset B., Dupont-Pavlovsky N., to be published.

[23] Price J. L., Venables J. A., Surf. Sci. 49 (1975) 264. 